\title{
Pengembangan Model Pembelajaran Group Investigation Media Vido Story Pokok Bahasan Keseimbangan Lingkungan Untuk Meningkatkan Berpikir Kritis Siswa
}

\section{Development of Learning Group Investigation Model with Vido Story Media subject of Environmental Balance to Improve Student Critical Thinking}

\author{
Sofiyati Awaliya $^{1 *}$, Ir. Hernik Pujiastutik ${ }^{2}$ \\ 1,2 Universitas PGRI Ronggolawe, Jln. Manunggal 61, Tuban, Indonesia \\ *Corresponding authors: prospective@unirow.ac.id
}

Manuscript received:

Revision accepted:

\begin{abstract}
Tuban Regency is one of the areas that holds the potential of nature, this can be seen from the number of large factories established in Tuban Regency. The existence of this large factory causes changes in the surrounding environmental balance. Based on the results of observation of learning in SMA Muhammadiyah 03 Bancar class X on the subject of environmental balance is still conventional with the lecture method and discussion of this matter leads to less interesting and boring learning therefore there needs to be a development of learning models where students can engage in a social solution Namely the Group Investigation learning model (GI). The purpose of this research is to develop a model of learning by using the environment as a learning medium that is packaged in the form of video story to cultivate students' critical thinking skills. The students' critical thinking ability can be measured from aspects of identifying problems, interpreting, giving relevant ideas and drawing conclusions. This type of research is a research development, which is the development of a learning model that is very appropriate for the material of environmental balance class X semester even, the resulting draft then validated by two experts and one teacher as a user. The results showed the average validation of two experts and one user is $83.529 \%$ which indicates valid criteria and is worthy of use. From the results of small-scale test results amounted to 15 students who analyzed with the normalized gain obtained $\mathrm{N}$ gain $>0.7$. These results indicate that there is a significant improvement in critical thinking of the students so that it can be concluded that the development of this learning model is very valid and feasible to be applied to improve critical thinking of the students.
\end{abstract}

Keywords: learning model, development, environmental balance, group investigation, critical thinking

\section{PENDAHULUAN}

Kabupaten Tuban merupakan salah satu daerah yang banyak menyimpan potensi alam, hal ini dapat dilihat dari banyaknya pabrik besar yang didirikan di Kabupaten Tuban. Keberadaan pabrik besar ini menyebabkan perubahan keseimbangan lingkungan disekitarnya. Pada pembelajaran IPA keseimbangan lingkungan merupakan materi yang dipelajari di kelas X semester genap. Materi keseimbangan lingkungan merupakan materi yang sangat penting dipelajari tidak hanya secara teoritis saja namun juga secara nyata, apa yang terjadi dilingkungan kita harus kita pelajari karena lingkungan merupakan tempat interaksinya semua komponen biotik dan abiotik. Manusia sebagai salah satu komponen biotik yang harus senantiasa memperhatikan, mempelajari dan menjaga keseimbangan lingkungan untuk kelestarian alam di masa mendatang.

Berdasarkan hasil observasi pembelajaran di SMA Muhammadiyah 03 Bancar kelas X pada pokok bahasan keseimbangan lingkungan masih bersifat konvensional dengan metode ceramah dan diskusi hal ini menyebabkan pembelajaran terkesan kurang menarik dan membosankan sehingga banyak siswa yang kurang antusias mengikuti pembelajaran. Kuranngnya antusias siswa dalam mengikuti proses pembelajaran akan menyebabkan kualitas sumber daya manusia (SDM) menurun, padahal peningkatan kualitas sumber daya manusia (SDM) perlu terus diupayakan sejalan dengan berkembagnya ilmu pengetahuan dan teknologi. Upaya tepat untuk membentuk sumber daya manusia yang berkualitas adalah dengan meningkatkan mutu pendidikan. Salah satu upaya yang sedang dilakukan pemerintah dalam meningkatkan mutu pendidikan IPA adalah melalui pembelajarann yang menekankan pada keaktifan dan kreativitas siswa serta pembelajaran yang selalu dikaitkan dengan penerapan materi dalam dunia nyata (bersifat kontekstual).

Salah satu model pembelajaran yang cocok dalam meningkatkan keaktifan dan kreativitas siswa serta penerapan materi dalam dunia nyata adalah model pembelajaran Gruop Investigation (GI). Dari beberapa model pembelajaran yang telah dipelajari peneliti dalam sebuah resume yang ditulis oleh Jumari (2011), model pembelajaran Group Investigation (GI) tertulis sebagai model pembelajaran yang paling kompleks dan paling sulit untuk dilaksanakan dalam pembelajaran kooperatif. Hal ini menggelitik peneliti untuk mempelajarinya lebih mendalam sehingga peneliti mencoba mengembangkan model pembelajaran Group Investigation (GI) pada 
pembelajaran Biologi pokok bahasan keseimbangan lingkungan untuk siswa kelas X SMA Muhammadiyah 3 Bancar tahun pelajaran 2016/2017. Model pembelajaran Group Investigation memiliki kelebihan yaitu terlatihnya siswa dalam bersosialisasi, memecahkan masalah, belajar berdemokrasi dalam penyatuan pemahaman terhadap materi dan siswa dapat berlatih mengkonstruk pemahaman terhadap materi. Hal ini dapat merangsang proses berpikir kritis siswa. Kemampuan berpikir kritis sangat diperlukan siswa SMA untuk menguasai konsep materi. Melalui kemampuan berpikir kritis siswa dapat mengembangkan keterampilan menggali dan mengevaluasi informasi, kemampuan mempertimbangkan keputusan dan tindakan yang diambilnya, serta keterampilan menganalisis dan menyelesaikan masalah dalam kehidupan sehari-hari.

Pengembangan kemampuan berpikir kritis seharusnya dapat dibantu guru melalui pemilihan dan penerapan model pembelajaran yang dapat melibatkan siswa secara fisik dan mental dalam proses pembelajaran (Deming, 2014) sehingga dalam dalam penelitian pengembangan ini peneliti mencoba mengkolaborasikan pengembangan model pembelajaran Group Investigation (GI) dengan media video story dengan pokok bahasan keseimbangan lingkungan. Untuk mengetahui kelayakan pengembangan model pembelajaran tersebut peneliti mengajukan judul “ Pengembangan Model Pembelajaran Group Investigation dengan Media Vidio Story Pokok Bahasan Keseimbangan Lingkungan Untuk Meningkatkan Berpikir Kritis Siswa”.

\section{METODE PENELITIAN}

Perangkat pembelajaran model Group Inverstigation dalam penelitian ini dikembangkan dengan mengikuti model Dick and Carey (2013) yang terdiri dari sepuluh tahapan dengan tujuan untuk menghasilkan prototype perangkat pembelajaran yang dapat meningkatkan berpikir kritis siswa. Komponen perangkat pemelajaran yang dikembangkan meliputi Silabus, Rencana Pelaksanaan Pembelajaran (RPP), Lembar Kerja Siswa (LKS), Media Pembelajaran dan Instrument Penilaian.

Penelitian eksperimen dilaksanakan di SMA Muhammadiyah 3 Bancar dengan menggunakan penelitian quaci eksperimen dengan desain Pre-test Post-test Control Group. Pengambilan sampel dalam penelitian ini adalah kelas X SMA Muhammadiyah 3 Bancar berjumlah 15 orang yang dipilih secara acak. Siswa di kelas X tersebut diberikan model pembelajaran GI untuk menguji efektivitas model tersebut.

\section{Analisis Data Kriteria Kelayakan Perangkat}

Data kualitatif yang dikumpulkan berdasarkan penilaian kelayakan perangkat oleh ahli mencakup empat katagori yakni, 5 untuk katagori sangat sesuai/sangat layak, 4 untuk katagori sesuai/layak, 3 untuk katagoricukup sesuai/cukup layak, 2 untuk katagori kurang sesuai/kurang layak dan 1 untuk katagori tidak sesuai/tidak layak. Aspek-aspek yang diamati dan dinilai oleh validator berdasarkan instrumen lembar validasi yang dibuat peneliti pada masing-masing perangkat pembelajaran yaitu : (a) Silabus, terdiri dari : isi silabus, bahasa dan waktu, (b) Rencana Pelaksanaan Pembelajaran (RPP) terdiri dari : perumusan tujuan pembelajaran, isi yang disajikan, bahasa dan waktu, (c) Lembar Kerja Siswa (LKS) terdiri dari isi yang disajikan dan bahasa, (d) media pembelajaran terdiri dari : penyajian, bahasa dan waktu, (e) instrumen penilaian terdiri dari penyajian, isi dan bahasa. Selanjutnya data penilaian kelayakan masing-masing perangkat pembelajaran ditabulasi dan dihitung rata-rata skor, kemudian diubah menjadi nilai dalam bentuk kriteria. Adapun kriteria tersebut dapat dilihat pada tabel 1 berikut ini B. Subali (2012).

Tabel 1. Kriteria nilai rerata total skor masing-masing komponen

\begin{tabular}{ccc}
\hline Nilai & Interval Skor & Katagori \\
\hline A & $80 \%<$ Skor $\leq 100 \%$ & Sangat valid \\
B & $60 \%<$ Skor $\leq 80 \%$ & Valid \\
C & $40 \%<$ Skor $\leq 60 \%$ & Tidak valid \\
D & $20 \%<$ Skor $\leq 40 \%$ & Sangat tidak \\
\end{tabular}

Sumber: B. Subali (2012)

Nilai kelayakan produk dalam penelitian ini ditetapkan minimal "B" kriteria layak. Dengan demikian, hasil penilaian validator jika member hasil akhir " $\mathrm{B}$ " atau layak, maka produk pengembangan layak digunakan dalam uji coba produk. Namun sebelum diuji coba, terlebih dahulu masing-masing perangkat pembelajaran tersebut direvisi sesuai dengan komentar/saran yang dikemukakan diakhir lembar validasi perangkat.

\section{Analisis Data Kemampuan Berpikir Kritis}

Data post-test kemampuan berpikir kritis yang diperoleh ditabulasi kemudian dihitung nilai rata-ratanya. Data posttest kemampuan berpikir kritis ini digunakan untuk menguji hipotesis. Uji hipotesis digunakan untuk mengetahui : Apakah ada peningkatan kemampuan berpikir kritis siswa yang belajar dengan perangkat pembelajaran model Group Investigation (GI). Uji hipotesis penelitian menggunakan uji-t dengan taraf signifikansi 5\%. Kriteria pengujian hipotesis : Ho ditolak apabila thitung $>$ ttabel atau nilai $\mathrm{p}>0,05$ maka Ho diterima, demikian sebaliknya jika $\mathrm{p}<0,05$ maka Ho ditolak.

\section{HASIL PENELITIAN DAN PEMBAHASAN} Hasil Penelitian

Perangkat pembelajaran yang terdiri atas Silabus, Rencana Pelaksanaan Pembelajaran (RPP), Lembar Kerja Siswa (LKS), Media Pembelajaran dan Instrument Penilaian yang digunakan dalam penelitian, sebelum digunakan telah mengalami validasi oleh 3 orang ahli. Hasil validasi terhadap perangkat pembelajaran yang dikembangkan sebagai berikut. 
Tabel 2. Rekapitulasi Hasil Penilaian Perangkat Pembelajaran.

\begin{tabular}{cccc}
\hline $\begin{array}{c}\mathrm{N} \\
\mathrm{o}\end{array}$ & $\begin{array}{c}\text { Perangkat } \\
\text { Pembelajaran }\end{array}$ & $\begin{array}{c}\text { Persentase } \\
\text { Rata-rata }\end{array}$ & Kualifikasi \\
\hline 1. & $\begin{array}{c}\text { Silabus } \\
\text { Rencana }\end{array}$ & $88,35 \%$ & Sangat valid \\
2. & $\begin{array}{c}\text { Pelaksanaan } \\
\text { Pembelajaran } \\
\text { (RPP) }\end{array}$ & $84 \%$ & Sangat valid \\
3. & $\begin{array}{c}\text { Lembar Kerja } \\
\text { Siswa (LKS) } \\
\text { Media }\end{array}$ & $80 \%$ & Valid \\
4. & $\begin{array}{c}\text { Pembelajaran } \\
\text { Instrument } \\
\text { Penilaian }\end{array}$ & $82,295 \%$ & Sangat Valid \\
5. & $83 \%$ & Sangat Valid \\
\hline & Rata-rata & $83,529 \%$ & Sangat Valid \\
\hline
\end{tabular}

Hasil pada Tabel.2 menunjukkan bahwa skor rata-rata perangkat pembelajaran yang dikembangkan sebesar $83,529 \%$, skor ini berada pada katagori sangat valid, ini berarti bahwa seluruh perangkat pembelajaran yang dikembangkan layak digunakan dalam penelitian. Hasil pada Tabel.2 juga menunjukkan bahwa pengembangan model pembelajaran Group Investigation dengan media pembelajaran berupa vidio Story sangat valid, praktis dan layak diterapkan di SMA Muhammadiyah 3 Bancar dengan materi Keseimbangan Lingkungan.

Hasil ini sesuai dengan penelitian Ely, Mardiyana dan Tri Atmojo (2013) menunjukan bahwa pengembangan model Pembelajaran GI Modifikasi berbantu video Camtasia merupakan model pembelajaran yang valid, praktis, dan efektif diterapkan serta sesuai dengan kurikulum 2013.

\section{Kemampuan Berpikir Kritis}

Data kemampuan berpikir kritis yang dideskripsikan dalam penelitian ini adalah skor rata-rata yang diperoleh subjek penelitian dari tes kemampuan berpikir kritis terkait materi keseimbangan lingkungan kelas $\mathrm{X}$ SMA. Tes yang diberikan untuk mengukur kemampuan berpikir kritis adalah tes berupa soal uraian. Nilai hasil tes keterampilan berpikir kritis siswa akan disajikan pada Tabel.3 dibawah ini.

Tabel 4. Nilai hasil pre-test tes keterampilan berpikir kritis.

\begin{tabular}{ccccc}
\hline No & Interval nilai & $\begin{array}{c}\text { Frekuens } \\
\text { i }\end{array}$ & Tuntas & $\begin{array}{c}\text { Tidak } \\
\text { tuntas }\end{array}$ \\
\hline 1. & $100-90$ & 1 & 1 & - \\
2. & $89-85$ & 3 & 3 & - \\
3. & $84-80$ & 1 & 1 & - \\
4. & $79-75$ & 2 & 2 & - \\
5. & $74-70$ & 2 & - & 2 \\
6. & $69-65$ & 3 & - & 3 \\
7. & $64-60$ & 1 & - & 1 \\
8. & $<60$ & 2 & - & 2 \\
& Jumlah & 15 & 7 & 8 \\
& persentase & $100 \%$ & $47 \%$ & $53 \%$ \\
\hline
\end{tabular}

Pada Tabel.4 menunjukkan bahwa tidak semua siswa mendapat nilai tuntas diatas kriteria ketuntasan minimal (KKM). Nilai KKM yang diterapkan disekolah tersebut adalah 75. Pada Tabel.3 menunjukkan bahwa dari 15 orang yang mengerjakan tes uraian kemampuan berpikir kritis terdapat 7 orang tuntas dan 8 orang tidak tuntas.

Tabel 4. Nilai hasil post-test tes keterampilan berpikir kritis.

\begin{tabular}{ccccc}
\hline No & Interval nilai & Frekuensi & Tuntas & $\begin{array}{c}\text { Tidak } \\
\text { tuntas }\end{array}$ \\
\hline 1. & $100-90$ & 2 & 2 & - \\
2. & $89-85$ & 5 & 5 & - \\
3. & $84-80$ & 2 & 2 & - \\
4. & $79-75$ & 4 & 4 & - \\
5. & $74-70$ & 1 & - & 1 \\
6. & $69-65$ & - & - & - \\
7. & $64-60$ & 1 & - & 1 \\
8. & $<60$ & - & - & - \\
& Jumlah & 15 & 13 & 2 \\
& Persentase & $100 \%$ & $86 \%$ & $13 \%$ \\
\hline
\end{tabular}

Pada Tabel.4 menunjukkan bahwa tidak semua siswa mendapat nilai tuntas diatas kriteria ketuntasan minimal (KKM). Nilai KKM yang diterapkan disekolah tersebut adalah 75. Pada Tabel.3 menunjukkan bahwa dari 15 orang yang mengerjakan tes uraian kemampuan berpikir kritis terdapat 12 orang tuntas dan 3 orang tidak tuntas.

Dari hasil pre-test dan post-test dapat diketahui bahwa terdapat peningkatan berpikir kritis siswa sebelum diterapkannya pengembangan model GI dan sesudah diterapkannya model pengembangan GI. Pada gambar 1 dapat dilihat hasil global pre-test dan post-test

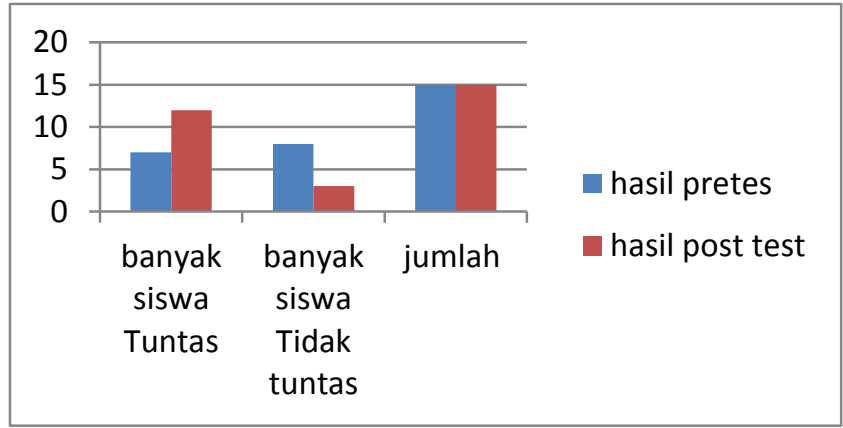

Gambar 1. Diagram hasil pre-test dan post-test keterampilan berpikir kritis siswa.

Untuk mengetahui ada tidaknya peningkatan berpikir kritis siswa setelah penerapan pengembangan model pembelajaran Group Investigation (GI), peneliti menggunakan rumus $\mathrm{N}$ gain. 
$N$ gain $=\frac{\text { skor tuntas postest }- \text { skor tuntas pretest }}{\text { skor ideal }- \text { skor tuntas pretest }}$

(Hake, 2010)

Kriteria gain ternormalisasi :

$\begin{array}{ll}\mathrm{N} \text { gain }<0,3 & \text { : peningkatan rendah } \\ 0,3 \leq \mathrm{N} \text { gain } \leq 0,7 & \text { : peningkatan sedang } \\ \mathrm{N} \text { gain }>0,7 & \text { : peningkatan tinggi }\end{array}$

Dari hasil penghitungan dengan menggunakan rumus $\mathrm{N}$ gain diperoleh hasil $\mathrm{N}$ gain sebesar 0,75 yang menunjukkan bahwa peningkatan kemampuan berpikir kritis siswa termasuk mengalami peningkatan yang tinggi karena $\mathrm{N}$ gain $>0,7$.

Untuk mengetahui pengaruh pengembangan model pembelajaran Group Investigation terhadap kemampuan berpikir kritis siwa dapat dianalisis dengan menggnakan rumus t-test.

$$
t=\frac{M d}{\sqrt{\frac{\sum x^{2} d}{N(N-1)}}}
$$

Uji hipotesis penelitian menggunakan uji-t dengan taraf signifikansi 5\% diperoleh hasil bahwa pengembangan model pembelajaran Group Investigation berpengaruh dalam meningkatkan kemampuan berpikir kritis siswa.

\section{Pembahasan}

Pengembangan model pembelajaran group investigation menggunakan model pengembangan Dick and Carey. Adapun tahapan pengembangan model Dick and Carey yaitu mengidentifikasi tujuan pembelajaran, melakukan analisis pembelajaran, menganalisis tingkah laku dan karakteristik siswa, merumuskan tujuan pembelajaran khusus, mengembangkan butir-butir tes acuan, mengembangkan strategi pembelajaran, mengembangkan dan memilih material pembelajaran, mendesain dan melaksanakan evaluasi formatif, merevisi pengembangan model pembelajaran.

Pengembangan model group investigation diawali dengan mengidentifikasi Kompetensi Inti dan Kompetensi Dasar dan tujuan yang terdapat dalam silabus. Setelah mengidentifikasi KI, KD, dan tujuan pembelajaran tahap selanjutnya adalah merumuskan dan mengembangkan Rencana Pelaksanaan Pembelajaran (RPP). Sebelum merumusan dan pengembangan Rencana Pelaksanaan Pembelajaran (RPP) terlebih dahulu peneliti melakukan analisis pembelajaran, menganalisis tingkah laku dan karakteristik siswa, merumuskan tujuan pembelajaran khusus, mengembangkan butir-butir tes acuan kemudian mengembangkan strategi dan model pembelajaran dalam hal ini adalah model pembelajaran Group Investigation (GI). Setelah mengembangkan mengembangkan strategi dan model pembelajaran peneliti memilih dan mengembangkan material pembelajaran. Salah satu material pembelajaran yang cocok dengan model Group Investigation (GI) adalah materi keseimbangan lingkungan, materi ini merupakan materi yang dipelajari di kelas $\mathrm{X}$ semester genap. Untuk memodivikasi model pembelajaran Group Investigation (GI) agar lebih menarik peneliti mengembangkan media pembelajaran berupa video story. Dalam video story ini ditayangkan perubahan keseimbangan lingkungan yang ada di Tuban, dampak dan upaya pelestariannya. Selain menarik video story ini juga berfungsi dalam hal efisiensi waktu, bayangkan jika siswa langsung diajak observasi langsung di lokasi maka akan memakan jam pembelajaran. Selanjutnya peneliti mendesain dan melaksanakan evaluasi formatif untuk mengukur berpikir kritis siswa dan merevisi pengembangan model pembelajaran setelah dilakukan validasi oleh 3 orang ahli. Hasil validasi ahli menyatakan bahwa pengembangan model Group Investigation valid.

Dari hasil pre-test pada Tabel.4, ketika siswa diberikan soal-soal dengan materi yang berkaitan dengan keseimbangan lingkungan, hanya sebagian kecil siswa saja yang mendapat nilai diatas Kriteria Ketuntasan Minimal (KKM). Berdasarkan Tabel.4 tampak 53\% siswa kurang memahami dan menguasai materi keseimbangan lingkungan karena siswa kurang mengaitkan fakta yang terjadi di lapangan dengan konsep-konsep sains (Zhou dkk, 2013). Siswa hanya pintar teori tetapi miskin aplikasi (Dewi, 2015). Hal ini disebabkan oleh kebiasaan belajar siswa yang masih kurang aktif di dalam pembelajaran. Kebiasaan belajar siswa terkait dengan model pembelajaran ceramah yang digunakan oleh guru.

Pembelajaran metode ceramah yang digunakan oleh guru belum melatihkan kemampuan berpikir kritis pada siswa. Sebagian guru menyatakan bahwa metode ceramah digunakan untuk membelajarkan materi keseimbangan lingkungan karena guru merasa kesulitan mengemas dan mengembangkan di dalam model pembelajaran. Pada materi keseimbangan lingkungan dengan kompetensi dasar menyajikan data tentang objek dan permasalahan biologi pada berbagai tingkatan organisasi kehidupan sesuai dengan metode ilmiah dan keselamatan kerja serta menyajikannya dalam bentuk laporan tertulis, kegiatan yang dilakukan seharusnya adalah pengamatan dan analisis lingkungan sekitar (Firdaus, 2013) tidak hanya sekedar teori saja, tetapi siswa melewati tahap-tahap yang melatihkan mereka untuk berpikir kritis (Rusli,2014).

Pada fenomena yang sering terjadi di kelas, kebanyakan siswa merasa kesulitan ketika dihadapkan pada fenomena dengan pengamatan langsung pada keseimbangan lingkungan. Hal ini dikarenakan karena materi keseimbangan lingkungan bersifat abstrak, padahal banyak sekali fenomena yang dapat direalisasikan dan digali dari lingkungan sekitar (Tartono, 2015).

Keterampilan berpikir kritis yang dibelajarkan pada materi keseimbangan lingkungan dapat memotivasi siswa untuk memiliki peduli terhadap lingkungan (Amini \& Munandar, 2010). Pembelajaran yang melatih berpikir kritis memiliki ciri melatih siswa untuk memprediksi, mengobservasi, menganalisis argument, melakukan eksplorasi, mengkomunikasi, menyimpulkan dan melakukan evaluasi. Ketika siswa terbiasa bertanya saat ada fenomena maupun permasalahan-permasalahan (Dewi, 2015) yang ditemukan selama pembelajaran, siswa terbiasa menyampaikan pendapatnya, melakukan konfirmasi terhadap jawaban atau mampu memberikan argument 
terhadap jawabannya, mampu menyimpulkan, melakukan eksplorasi dengan menggali sendiri informasi yang diperlukan selain yang didapatkan dari guru serta terbiasa mempresentasikan hasil pengamatannya, maka siswa tersebut telah memenuhi kriteria berpikir kritis. Apabila kebiasaan belajar siswa telah memenuhi komponen atau kriteria kemampuan berpikir kritis, maka secara otomatis kemapuan berpikir kritis telah dimiliki siswa tersebut. Dengan memiliki kemampuan berpikir kritis maka siswa akan mampu mencapai hasil belajar dengan baik (Dewi, 2015; Rosvida, dkk., 2015; Kinasih, dkk., 2015; Setiawan, dkk., 2015)

\section{KESIMPULAN}

Berdasarkan pembahasan dapat disimpulkan bahwa pengemangan model pembelajaran Group Investigation (GI) berbantu vidio story merupakan model pembelajaran yang valid, praktis dan efektif serta layak diterapkan pada materi keseimbangan lingkungan kelas $X$ di SMA Muhammadiyah 3 Bancar untuk meningkatkan berpikir kritis siswa. Keterampilan berpikir kritis perlu dimiliki siswa supaya mampu memahami materi pembelajaran dan memperoleh hasil belajar dengan baik. Keseimbangan lingkungan merupakan materi pembelajaran yang repesentatif untuk melatih keterampilan berpikir kritis. Materi keseimbangan lingkungan perlu dibelajarkan dengan model, metode dan strategi untuk melatih kemampuan berpikir kritis.

Berdasarkan kesimpulan tersebut, maka dapat disarankan untuk senantiasa menciptakan pembelajaran yang mengedepankan kreativitas siswa agar nantinya siswa mempunyai kemampuan berpikir kritis. Model pembelajaran Group Investigation (GI) dengan berbantu vidio story merupakan salah satu pilihan yang dapat dipakai oleh guru dalam pelaksanaan pembelajaran.

\section{UCAPAN TERIMAKSIH}

Pada kesempatan ini kami mengucapkan banyak terimakasih kepada semua pihak yang telah membantu terlaksananya penelitian ini baik ketika observasi maupun pada proses analisisnya. Terimakasih juga kami sampaikan kepada kaprodi pendidikan biologi yang telah memotivasi kami sehingga kami bisa mengikuti seminar nasional ini.

\section{DAFTAR PUSTAKA}

Amini, R \& Munandar, A. (2010). Pengaruh Model Pembelajaran Pendidikan Lingkungan Hidup Berbasis Outdoor Terhadap Penguasaan Konsep Pendidikan Lingkungan Hidup Bagi Calon Guru SD. Jurnal Penelitian Pendidikan. 11 (1) : 14 - 21

Deming, J. C \& M. S. Crawlice. 2014. Learning How to Think. The Science Teacher

Dewi, N., \& Riandi. (2015). Analisis Kemampuan Berpikir Kritis Sains Siswa SMP Kelas VII di Kota Sukabumi Melalui Pembelajaran Berbasis Masalah Pada Tema Pemanasan Global. Prosiding Seminar Nasional Fisika (E-Journal) SNF 2015. 4 : 151156

Firdos, N.A., Rudyatmi,E. \& Herlina, L. (2013). Penerapan Model Pembelajaran POE dengan Bantuan Media Foto pada Materi Struktur dan Fungsi Jaringan
Tumbuhan.Unnes Journal of Biology Education 2 (2) $\therefore 205-212$

Hake, R. R. 2010. Assesment of Physics Teaching Methods. Proceding of The UNESCO Asian Physics on Active Learning in Physics. Sri Lanka University of Pardenia. Tersedia di Http://www.physics.indiana.edu/-hake/ diakses pada 20 Juli 2017.

Jumari. (2011). Resume Model-model Pembelajaran. Purwokerto.

Kinasih, M. E., Jalmo,T. \& Berty, Y. (2015). Pengaruh Model Discovery Learning Terhadap Keterampilan Berpikir Kritis Siswa. Jurnal Bioterdidik FKIP Unila : 56 - 60. San Francisco, CA: Jossey-Bass.

Rosvida, F., Zubaidah, S., \& Mahanal, S. (2015). Kemampuan Bertanya dan Berpendapat Siswa SMA Negeri Batu Pada Mata Pelajaran Biologi. Prosiding Seminar Nasional Bio;ogi/IPA dan Pembelajarannya. UM Malang, 17 Oktober 2015. 1663 - 1684

Rusli. (2014). Penerapan Strategi Pembelajaran Inquiry untuk Meningkatkan Keterampilan Berpikir Kritis Siswa Pada Materi Struktur dan Fungsi Tumbuhan. Jurnal Edu Bio . 2 . 121 - 186

Setiawan, D., Zubaidah, S., \& Mahanal.S. (2015). Pengaruh Penerapan Model Reading Concept Map Thik Pair Share Terhadap Minat Baca, Hasil Belajar, Kemampuan Metakognitif dan Berpikir Kritis Siswa Kelas X di Kota Malang. Prosiding Seminar Nasional Biologi/ IPA dan Pembelajarannya. UM Malang, 17 Oktober 2015. 798 - 805

Subali, B., dkk. (2012). Pengembangan CD Pembelajaran Lagu Anak untuk Menumbuhkan Pemahaman Sains Siswa Sekolah Dasar. Jurnal Pendidikan Fisika Vol.1. No.8

Tartono. (2015). Pembelajaran Materi Tumbuhan Melalui Penerapan Metode Pembelajaran Problem Based Learning. Jurnal PTK 10(3), 68-78.

Widoyo, E., Mardiyana, \& Tri Atmojo.K. (2013). Pengembangan Model Pembelajaran Group Investigation Berbantu Vidio Camtasia Pada Materi Peluang untuk Siswa SMA/MA Negeri Kabupaten Cilacap Tahun Pelajaran 2013/2014. Jurnal elektronik Penndidikan Matematika Vol.2, No.5. 478 - 490

Zhou, Q., Huang, Q., \& Tian, H. (2013). Developing Students Critical Thinking by Task- Based Learning in Chemistry Experimen Teaching. Creative Education Science Research 4 (12A), 40-45. 